
Table 1-Comparison of internal malignancies
between patients with multiple basal cell carcinomas between patient
and controls

\begin{tabular}{lcc}
\hline Malignancy & Cases & Controls \\
\hline Haematological $^{*}$ & 5 & $0 \dagger$ \\
Breast & 3 & 1 \\
Gastrointestinal tract & 1 & 2 \\
Genitourinary tract & 4 & 4 \\
\hline Total & 13 & 7
\end{tabular}

"Four patients had non-Hodgkin's lymphoma and one had chronic myeloid leukaemia. package).

observation of a link between non-Hodgkin's lymphoma, malignant melanoma, and squamous cell skin cancer. ${ }^{2} \mathrm{He}$ did not, however, assess any association with basal cell carcinoma, the commonest malignancy in white people.

Exposure to ultraviolet radiation is recognised as a critical factor in the pathogenesis of basal cell carcinoma, presumably partly because of resulting immune suppression. ${ }^{3}$ It could therefore be hypothesised that an association would exist between basal cell carcinoma and malignancies associated with immune suppression, such as haematological neoplasms. ${ }^{4}$ Importantly, many patients with basal cell carcinoma develop multiple lesions, and it might be presumed that these subjects represent a group with high susceptibility -that is, one at greatest risk of internal malignancy. We report findings from a case-control study to identify an association between multiple basal cell carcinoma and haematological malignancy.

Altogether 141 white patients from northern Europe (mean age $71 ; 62$ women) with histologically proved primary basal cell carcinoma (range 2-35 tumours per patient) were recruited over 18 months from dermatological outpatient clinics and followed up for roughly three years. Patients with other types of skin cancer or Gorlin's syndrome were excluded. Controls matched for age and sex (one case to one control) who had benign skin conditions (benign naevi, 67; eczema, 47; leg ulcers, 10; rosacea, 7 ; others, 10) were recruited in the same clinics. The presence of any histologically proved internal or haematological malignancy in cases or controls was noted. Thirteen cases, compared with seven controls, had an internal malignancy (table 1). This difference was not significant, though the difference between the number of cases (5) and controls (0) with a haematological malignancy approached significance. Four of the five cases developed the haematological malignancy after developing their first basal cell carcinoma.

Our pilot study suggests a link between basal cell carcinoma and haematological malignancy. Such a link would have implications for follow up and understanding of the pathogenesis of this malignancy.

We acknowledge the support of the Cancer Research Campaign in this study.

Senior registrar in dermatolog A G SMITH

Consultant dermatologist A A FRYER

Clinical biochemis R C STRANGE

Professor of clinical biochemistry North Staffordshire NHS Trust, Stoke on Trent ST4 7PA

$P$ W JONES

Professor of mathematic

Keele University,

Keele ST5 5BG

1 Bentham G. Association between incidence of non-Hodgkin's lymphoma and solar ultraviolet radiation in England and Wales. BMf 1996;312:1 128-31. (4 May.)
2 Adami J, Frisch M, Yeun J, Glimelius B, Melbye M. Evidence of an association between non-Hodgkin's lymphoma an skin cancer. $B M \mathcal{F}$ 1995;310:1491-5.

3 Kripke ML. Immunological effect of ultraviolet radiations. Dermatol 1991;18:429-33.

4 Hoover R, Fraumeni JF. Risk of cancer in renal transplant recipients. Lancet 1973;ii:55-7.

\section{Peanut and nut allergy}

\section{Creams and ointments containing peanut} oil may lead to sensitisation

EDrToR,-Pamela W Ewan suggests that peanut allergy in children is due to the ingestion of peanut butter before the age of 1 year but acknowledges that some children react after their first known exposure. ${ }^{1}$ She supposes that minute amounts of allergen might be present in breast milk or hidden in foods, but it is not widely appreciated that arachis oil (peanut oil) is present in many preparations that are applied topically. Breast feeding mothers often treat sore nipples with chamomile ointment, the main ingredient of which is arachis oil. Presumably some of this is ingested by the infant, which could lead to sensitisation.

Children might also become sensitised to peanut allergen through skin contact. Despite the name, zinc and castor oil ointment, which is often used to treat napkin dermatitis, is $30 \%$ peanut oil. Napkin eruptions are common in children with atopic dermatitis, and absorption of allergens is increased across broken or inflamed skin, so sensitisation to peanuts could occur in this way. Certainly, skin contact leading to sensitisation occurs with other allergens, and although no evidence exists of specific induction of peanut allergy by this route, I prefer not to recommend the use of creams or ointments that contain arachis oil.

Department of Dermatology,

LAURENCE R LEVER Northwick Park Hospital

Harrow,

Middlesex HAl 3UJ

1 Ewan PM. Clinical study of peanut and nut allergy in 62 consecutive patients: new features and associations. $B M$ 1996;312:1074-8. (27 April.)

\section{Baby massage oils could be a hazard}

EDITOR,-The recent articles on peanut allergy do not mention the fact that baby massage is becoming popular and that the oils used in this might pose a hazard. ${ }^{12}$ If tiny babies suck their hands after a hand massage with arachis (peanut) oil they may ingest large quantities of nut products. Special care baby units such as that at Queen Charlotte's and Chelsea Hospital recommend arachis oil for massages of premature babies. Perhaps the potential risk should be indicated on the labels of massage oils and in baby massage books and at classes. Alternative products could be used.

RACHEL JOYCE

Department of Public Health,

Merton, Sutton, and Wandsworth Health Authority,

Mitcham,

Surrey CR4 4TP

Department of Otorhinolaryngolog Northwick Park Hospital Trust,

Harrow,

Middlesex HA1 3UJ

1 Sampson HA. Managing peanut allergy. $B M f$ 1996;312:1050-1. (27 April)

2 Ewan PW. Clinical study of peanut and nut allergy in 62 consecutive patients: new fearures and associations. $B M$ 1996;312:1074-8. (27 April.)
Serious adverse reactions to adrenaline are becoming more likely

EDITOR,-Pamela W Ewan's findings with regard to peanut and nut allergy ${ }^{1}$ agree with my personal experience of the problem: such allergy occurs in otherwise atopic subjects, it is acquired early (possibly in utero in some cases), and after the first adverse reaction sufferers are almost invariably aware of the problem-although in some this is at a subconscious level, and they become averse to all nuts without remembering the reason.

I doubt, however, Ewan's implication that the problem is becoming much more common. It is difficult to obtain meaningful figures of prevalence in the past, but I have estimated a probable prevalence of hypersensitivity to any nut of between $1 \%$ and $5 \%$ in the population from which my patients have been drawn over some 30 years, and without much variation. Previously, those affected knew that they could not eat nuts, avoided them assiduously, were generally free of symptoms, and did not consult a doctor, which explains the medical profession's lack of awareness of the problem in the past. Those affected were detected, if at all, when they attended allergy clinics for investigation of other manifestations of atopy. Now, on the other hand, as a consequence of publicity generated by such organisations as the Anaphylaxis Campaign and British Allergy Foundation, ${ }^{2}$ many people who managed very well by themselves over many years have been informed that they must seek medical advice and be referred to clinics, where investigation confirms only what they know already.

A consequence of this is that we are seeing a true increase in serious adverse reactions to adrenaline injections, which are now being offered routinely to such patients and used for any symptoms, whether trivial or even unrelated to hypersensitivity. Parenteral adrenaline certainly plays a major part in the management of dangerous anaphylaxis and angio-oedema, but these are exceedingly rare (especially when one considers the high prevalence of sensitivity to nuts), and they probably usually involve additional, non-atopic factors. Avoidance remains the golden rule and is usually practised successfully because the patient's tongue and lips are aware of traces of the allergen in prepared foods to which the patient has been blinded. Better labelling of foods would help, but I fear that we may see more frequent dangerous episodes, including deaths, due to adrenaline than to anaphylaxis unless a more measured response to the problem is developed.

JOHN A WILSON Consultant in allergy and clinical immunology Royal Liverpool University Hospitals, Liverpool L7 8XP

1 Ewan PW. Clinical study of peanut and nut allergy in 62 consecutive patients: new features and associations. $B M f$ 1996;312:1074-8. (27 April.)

2 Sampson HA. Managing peanut allergy. $B M f$ 1996;312:1050-1. (27 April.)

\section{Study was not designed to measure} prevalence

EDITOR,-Media coverage of Pamela W Ewan's study of peanut and nut allergy ${ }^{1}$ - for example, in BBC Radio 4's PM programme-highlighted the conclusion in the abstract that "peanut and nut allergy is becoming common"; we note that in the key message this statement has become "peanut and nut allergy are becoming more common." The study, however, was not designed to measure the prevalence of such allergies and, indeed, was restricted to patients seen during one year at a particular allergy clinic; the only evidence given in support of the supposed 
conclusion is the author's "impression that the increased incidence of peanut or nut allergy is real" and the statement that "there has been a considerable increase in the rate of referrals for food allergy." Even more disturbingly, Hugh A Sampson cites this study in his editorial in support of his conclusion that "the prevalence of peanut and nut allergy is increasing."

While the incidence of nut allergy may indeed be rising, we believe that authors have a responsibility not to overstate their case, particularly on issues that are likely to be of interest to the media. Ewan should provide us with the evidence that led her to conclude that nut allergy is becoming common so that we can decide on this important issue, for ourselves and for our patients.

SHEILA JONES

Research associate

Department of Clinical Dental Sciences,

try of Liverpool

Liverpool L69 3BX

IAN JONES

639 Chorley New Road,

General practitioner

Lostock,

Bolton BL6 4AA

1 Ewan PW. Clinical study of peanut and nut allergy in 62 consecutive patients: new features and associations. $B M f$ 1996;312:1074-8. (27 April.)

2 Sampson HA. Managing peanut allergy. $B M F$ 1996;312:1050-1. (27 April.)

\section{Reduced exposure might increase allergic sensitisation}

EDIToR,-Pamela W Ewan makes the important statement that the incidence of peanut and nut allergy is rising and that sensitisation seems to occur early in life. ${ }^{1}$ Regrettably, she does not provide any evidence to back her recommendation that "young allergic children should avoid peanuts and nuts to prevent the development of this allergy" and her extraordinary suggestion that avoidance should be practised until the age of 7 . Hugh A Sampson, in the accompanying editorial, makes similar recommendations and further suggests that mothers who are breast feeding should eliminate peanuts from their diet. ${ }^{2}$

Firstly, there is no evidence that avoiding foods during lactation or early childhood prevents allergic sensitisation to these foods. Indeed, in certain cultures that consume large quantities of peanuts, peanut allergy seems to be less of a problem than it is in Britain. Secondly, allergic sensitisation may occur in utero, but no advice is given on maternal diet during gestation. Thirdly, exposure to peanuts and other food allergens during lactation and childhood may be important in the development of immunological tolerance and may prevent allergic sensitisation to these foods. Finally, avoidance measures would serve only to reduce exposure to peanuts to low levels, and this could paradoxically increase allergic sensitisation to peanuts: low dose exposure to allergens (rather than high dose exposure) favours production of $\operatorname{IgE},{ }^{3}$ and as little as $1 \mu \mathrm{g}$ of inhaled allergen a year may be sufficient to induce allergic sensitisation via the airways. ${ }^{4}$

Prospective data comparing consumption of peanuts by children who are allergic to them and by atopic controls are required before broad policy recommendations are made. History contains far too many examples of uninformed health policies that were based on insufficient data and achieved unintended effects.

Professor of paediatric and perinatal epidemiology Department of Child Health,

Royal Hospital for Sick Children,

Bristol BS2 8BJ
1 Ewan PW. Clinical study of peanut and nut allergy in 62 consecutive patients: new features and associations. $B M 9$ 1996;312:1074-8. (27 April.)

Sampson HA. Managing peanut allergy. $B M \mathscr{T}$ 1996;312:1050-1. (27 April.)

3 De Kruyff RH, Fang Y, Umetsu DT. IL-4 synthesis by in vivo primed keyhole limpet hemocyanin-specific CD4+ T cells. I Immunol 1992;149:3468-76.

4 Platts-Mills TAE. Atopic allergy: asthma and atopic dermatitis. Curr Opin Immunol 1991;3:874-80.

\section{Author's reply}

EDITOR,-I am aware that various creams (for eczema, cracked nipples, and massage) contain arachis (peanut) oil. While these are possible sources of sensitisation, it has not yet been established whether this oil is allergenic. One study showed no effect of giving arachis oil orally to patients who were allergic to peanuts, ${ }^{1}$ whereas another showed that it exacerbated eczema. ${ }^{2}$ Such products have exacerbated eczema in some of my patients. More data are needed, and research is in progress. The makers of chamomile ointment are reformulating their product without arachis oil.

John A Wilson and Sheila Jones and Ian Jones question my suggestion that the incidence of peanut allergy has increased. This is based on 16 years' experience in major allergy centres. The rise in referrals began in the early 1990s. Studies are under way to measure prevalence, but one difficulty will be that no previous data exist. If Wilson has population based data on prevalence then he should publish them. Some of the rise will be due to increased public awareness, but I believe that a real change has also occurred. I have data showing that the age at sensitisation is falling, and most of the 62 patients on whom I reported had become allergic by the age of 2-that is, the cases were of recent onset.

Wilson questions the value of diagnosis and management. At the allergy clinic our approach is two pronged. Avoidance is the key, and expert advice is essential since peanuts and nuts are now often hidden in foods. Many of the children who died knew that they were allergic (exactly as Wilson describes), practised avoidance, but had not had professional advice. Secondly, we provide drugs for self treatment of reactions after inadvertent ingestion. This does not always mean adrenaline for injection (unpublished data).

My advice was that young atopic children (not all children) should avoid peanuts and nuts because of the strong association (96\%) with other atopic disease. I agree with Gideon Lack and Jean Golding, however, that more studies are needed. I postulate that factors that are important in the increase in peanut allergy are the increase in atopic disease and early and increased exposure to peanuts. Avoidance can reduce sensitisation to food allergens, ${ }^{3}$ but the effects of the dose of antigen on the production of cytokines are complex (S M Hugh et al, unpublished findings). ${ }^{4}$ Genetic and other factors are clearly important in induction of the Th2 phenotype.

PAMELA W EWAN

Allergy Clinic

Addenbrooke's Hospital NHS Trust,

University of Cambridge Clinical School,

Cambridge CB2 2QH

1 Taylor SL, Busse WW, Sachs MI, Parker JL, Yuninger JW. Peanut oil is not allergenic to peanut-sensitive individuals. f Allergy Clin Immunol 1981;68:372-5.

2 Monet-Vautrin DA, Harahet R, Kanny G, Ait-Djafer Z. Allergenic peanut oil in milk formulas. Lancet 1991;338:1149.

3 Zeiger RS, Heller S, Mellon MH, Forsyth AB, O'Connor RD, Hamburger RN, et al. Effect of combined maternal and Hamburger RN, et al. Effect of combined maternal and
infant food-allergen avoidance on development of atopy in infant food-allergen avoidance on development of atopy in
early infancy: a randomized study. 9 Alergy Clin Immunol early infancy: a

4 McHugh SM, Deighton J, Rifkin IR, Ewan PW. Kinetics and functional implications of Th1 and Th2 type cytokine production following activation of peripheral blood mononuclear cells in primary culture. Eur $f$ Immuno 1996;26:1260-5.

\section{Sesame allergy is also a problem}

EDrroR,-Hugh Sampson's editorial on managing peanut allergy omits one important point ${ }^{1}$ : medical identification bracelets should be worn at all times. Unsurprisingly, attention focuses on peanuts, ${ }^{2}$ but sesame allergy, although less common than peanut allergy, can be every bit as severe. Sesame is used extensively in the food industry, and the seeds present a danger because of their versatility. ${ }^{3}$ I report here my most recent allergic reaction to sesame. I was looking forward to an evening out with my daughter in law: a meal in a restaurant and then a visit to a theatre. I telephoned the restaurant to advise it of my serious allergy and then packed my "survival kit" (injectable adrenaline, an adrenaline inhaler, and a note that backs up my Medic-Alert bracelet). After my first anaphylactic shock in 1981 I was issued with an American kit containing a pre-filled adrenaline syringe and tablets of chlorpheniramine maleate. Eventually, this was replaced with the standard injectable adrenaline that is issued by the NHS. I had never felt comfortable with this: it had to be assembled before use, and I wondered how I would cope in an emergency.

I reminded the restaurant staff about my allergy; I always feel a bit uneasy when eating out. A glass of champagne calmed my nerves, and then the soup arrived. I tend to avoid soup when eating out, ${ }^{4}$ but this was made in house and I was assured that it did not contain sesame. It did. Within seconds my mouth started to tingle, my ears burnt, my neck flushed, and my hands started to itch - characteristic signs of an allergic reaction. I rinsed out my mouth and tried to assemble the syringe. Impossible! Could anyone, in such a stressful situation? I cursed the syringe, abandoned it, and used my inhaler instead. The restaurateur was frantic: "Is there a doctor in the house?" There wasn't.

We sat outside and waited for an ambulance. I was gasping for breath and wanted to be sick. I was. A warm glow came over me, and everything just faded away. In the ambulance the paramedics clamped an oxygen mask on my face. My son, who must have driven like Fangio, arrived at the hospital just as the casualty officer was preparing an injection. I smiled when I heard his voice: "Excuse me, my mother is allergic to sesame; it's used in some drugs. " ${ }^{\text {We }}$ had done our homework.

57 Goodyers Avenue,

Radlett WD7 8AZ

1 Sampson HA. Managing peanut allergy. $B M \mathcal{F}$ 1996;312:1050-1. (27 April)

Perkins MS. Sesame warning. Pharmaceutical fournal 1995;254:782.

3 Perkins MS. Seeds of success. British Allergy Foundation Allergy Neros 1995 Jul:4-5.

4 Ministry of Agriculture, Fisheries and Food. Labelling anomalies. Food allergy booklet. London: MAFF, 1995:7. (PB1696.)

5 Kägi MK, Wüthrich B. Falafel burger anaphylaxis due to sesame seed allergy. Ann Allergy 1995;71:127.

\section{Value of ECGs in identifying heart failure due to left ventricular systolic dysfunction}

EDITOR,-We wish to reply to the letters ${ }^{1}$ about our short report. ${ }^{2}$

We are pleased to learn that Suresh Khandekar and colleagues are following our example in using electrocardiography to identify heart failure due to left ventricular systolic dysfunction, but we do not understand why they use an automated report for interpreting electrocardiograms. While we appreciate Kamlesh Khunti and Robert McKinley's concerns about the interpretation of electrocardiograms in general 